\title{
SWOT Analysis of the Air Transport Fleet in the Hungarian Defence Forces
}

\author{
Adrienn Boldizsár ${ }^{1 *}$, Botond Kővári \\ 1 Department of Transport Technology and Economics, Faculty of Transportation Engineering and Vehicle Engineering, Budapest \\ University of Technology and Economics, H-1521 Budapest, P. O. B. 91, Hungary \\ * Corresponding author, e-mail: b.adri9312@gmail.com
}

Received: 20 November 2018, Accepted: 01 February 2019, Published online: 16 December 2019

\begin{abstract}
Nowadays it is almost unthinkable, that the forces of the army can not deliver the resuply to the troops by air, especially for large distances. This can not be solved by sea or inland transportation, or if it does, it will take unnecessary time or less security. Although the Hungarian Defense Forces have their own transportation fleet, the fleet reserved for this purpose is currently very modest, and there are several reasons why it should be expanded. Developing an own airline fleet is currently a very topical issue. Previously operated Antonov 26 aircraft have little ability to perform the tasks, or in many cases cannot. The two Airbus A319 aircraft purchased in February and Falcon type aircraft purchased in August, although improves the situation, they still do not fill the gap, there are a number of deficiencies in this area. For this I did a SWOT analysis, and with its help we can define the opportunities and threats of development of domestic military air transport.
\end{abstract}

Keywords

Hungarian Defence Forces, military air transport, SWOT analysis

\section{Introduction}

There is no question that the air carrier capacity of our country should be increased. This would not have the purpose of moving troops inside country borders, because of the small distances, but it is necessary to perform international tasks with allied forces. In 2017, the Hungarian Defence Forces needed to rent an airplane for 55 times. In addition, last year 19 times, and 23 times this year, had to return urgently sick or injured soldiers from operational area. This vulnerable situation can be eliminated, for example, by purchasing Airbus 319 aircraft and providing strategic airlift, but this is still not enough to satisfy the real needs.

One basic element of the Hungarian Defense Forces' shipping fleet is the Antonov 26, which was previously described, but the running time of these machines is about to expire. Currently there is only one operational aircraft in existence, which should have been officially withdrawn from the last major overhaul in 2015 as the maximum extended service life has expired. By contrast, they are still in the sky today, which poses a serious safety risk, not to mention that it does not suit for environmental reasons as well, and can not even get a landing permit at some airports. Despite this, there is still talk of prolonging the operating time (Derzsényi, 2014).
The purchase of the Airbus A319 may seem like a logical step to solve the real shortage and problems, but it can be seen that this is not the case for servicing an entire nation's military deliveries, especially considering that these aircraft are mainly intended to serve the personnel. It is important to note that the second plane is a VIP machine, and it will most likely carry only the head leaders of the country and has not been presented to the general public either (Derzsényi, 2014).

\section{SWOT analysis of Hungarian military air transport fleet}

Prepearing the calculation I made the SWOT analysis of the air transport fleet of the Hungarian Army, which helped define the development directions more easily. The SWOT analysis is shown in Table 1. SWOT is an acronym, meaning (MindTools):

- S (Strengths): examine the strengths of the product. Which is better than the others, it should be emphasized.

- W (Weaknesses): the recognition of weaknesses and the possibilities for correcting them. 
Table 1 SWOT analysis (self-editing)

\begin{tabular}{|c|c|}
\hline Strengths & Weaknesses \\
\hline $\begin{array}{l}\text { - The very high speed of air transport. } \\
\text { - It is the most efficient way of transporting at long distances. } \\
\text { - Newly procured Airbus A319 and Dassault Falcon 7X airplanes. }\end{array}$ & $\begin{array}{l}\text { - It is very expensive to operate and maintain of the aircraft. } \\
\text { - Airport maintenance is expensive. } \\
\text { - Deliveries over } 6800 \mathrm{~km} \text { can not be solved at own resourches of } \\
\text { the Defense Forces. } \\
\text { - Limited capacity. } \\
\text { - High infrastructure needs. }\end{array}$ \\
\hline Opportunities & Threats \\
\hline $\begin{array}{l}\text { - High development opportunities. } \\
\text { Thanks to the NATO membership, Defense Forces must keep } \\
\text { a high level. } \\
\text { - } \\
\text { Payed transfer by a larger transport fleet. } \\
\text { - } \text { Significant decrease of costs for own fleet. }\end{array}$ & $\begin{array}{l}\text { - The expired operating time of Antonov } 26 . \\
\text { - Labor shortage between technikal officers. } \\
\text { - Need for rented vehicles. } \\
\text { - Transport demand disappearance. }\end{array}$ \\
\hline
\end{tabular}

- O (Opportunities): exploring of opportunities.

- T (Threats): discovering hazards, and avoiding them.

\subsection{Strength}

\subsubsection{Very high speed of air transport}

The huge advantage of air transport against road or railway sectors is that the long distances can be bridged within a fraction of the time. The existence of a transport fleet is a great advantage even with a minimum number of machines, especially in the life of an army if almost immediately or within a finite time to respond to a given situation (such as rescue missions, immediate resuply, etc.).

\subsubsection{It is the most efficient way of transporting at long} Currently and most likely also in the future none of the transport sector can compete with air transport as to how quickly the huge distances can be bridged.

\subsubsection{Newly procured Airbus A319 and Dassault Falcon 7X airplanes}

Among the strengths, it is important to mention the two Airbus A319s purchased this year, which helping it will most likely require much less the other Air Force forces. The movement and transportation of the troops have become self-sustainable as well as the transportation of state and military leaders become easier to handle by purchasing these aircraft.

\subsection{Weaknesses}

2.2.1 To operate and maintain aircraft is very expensive It can be said from the air transport that it is practically the most costly way of transport, and this is not the case in military applications either. One of the main reasons for this is the means of transport itself and the airplane, which ranges from purchase, operation, fuel consumption, all at a high cost. In this area, we can not even talk about spares, since it can even lead to a fatal accident if the aircraft does not receive the proper operating and maintenance line at all times.

\subsubsection{Airport maintenance is expensive}

An additional cost factor appears with the location of the aircraft server, namely the airports. In order to be able to apply them appropriately, it also means a huge cost burden starting with the investment through the operation.

\subsubsection{Deliveries over $6800 \mathrm{~km}$ can not be solved at the moment by the Defense Forces}

The Antonov 26's maximum service distance is $2600 \mathrm{~km}$. However, the Airbus A319s purchased this year are able to carry a distance of about 2.5 times, but in this case we are not talking about the maximum carry-over load. Since Boeing C17 Globemasters are not the property of the Hungarian Defense Forces, we can not talk about larger distances that could be solved by our own capacity (HM Zrínyi Nonprofit Kft.).

\subsubsection{Limited capacity}

One of the most commonly mentioned disadvantage of air transport is the limited capacity, that is, both the weight and the volume are finite depending on the size of the transport aircraft. Here furthermore limited capacity can be interpreted, for example, not once or even recently, there was not a sufficient number or even a viable transport aircraft for performing the tasks.

\subsubsection{Large infrastructure needs}

This weakness is also a part of air traffic as the specific characteristics of the transport sector. True, airplanes in military use can in many cases be able to perform under extreme 
conditions, for example, it is not necessary to have a solid paved runway, but the optimal condition for them is the airport with the right infrastructure, which in many cases means serious investment, equipment and costs.

\subsection{Opportunities}

\subsubsection{High degree of development possibility}

Because of the domestic military carrier fleet is currently not capable of supplying in $100 \%$ of the total air transport missions, therefore it can be stated that there are still many development opportunities in this area of the Hungarian Defense Forces.

\subsubsection{Thanks to the NATO membership, Defense Forces must keep a high level}

Thanks to the NATO membership, it is a basic requirement that the Hungarian Defense Force has to have some air transport capacity, which means that the country has to spend $2 \%$ of the country's GDP per year for defense funding, so maintaining and developing air transport capacity can be included in these costs (HM Zrínyi Nonprofit Kft.).

\subsubsection{Payed freight transport with the possibilty of larger transport fleet}

With a possibly larger transport fleet would not only be able to supply our own tasks easily, but other air carriers could also be involved in wage transfers, which could also mean revenue for the Hungarian Defense Forces.

\subsubsection{Rapid response to unexpected situations}

Hungarian Army can respond to unexpected situations much faster and easier with a well-functioning and proper size airfleet.

\subsubsection{Significant decrease of costs incase of own fleet}

The disappearance of either help of payed transfer or continuously appearing rental costs, in the long term with an own carrying capacity it will be always more profitable and more economical, than a service of foreign transport aircraft. In addition, the training and maintenance of the flight crew could be more effectively solved with the use of an own fleet.

\subsection{Threats}

\subsubsection{The expired operating time of Antonov 26}

The currently operating Antonov 26 plane has already expired, in fact, the extended deadline has since gone too far. This is a serious safety risk.

\subsubsection{Labor shortage among technician officers}

It is a real actual problem the shortage of staff among technically trained military officers, which can lead to technical problems and, in extreme cases, to an aircraft disaster.

\subsubsection{Need for rented vehicles}

This factor does not necessarily mean a direct source of danger, but at the same time, there may be a situation where it would be necessary to provide some kind of air transporting assistance to a military soldier wheter he is abroad in a foreign country in a mission serving our country, or he is inside the country. For this, if an airplane is unavailable and we may have to lean on others in this situation, the person in trouble may not receive our help in time.

An interesting example is the 2004 Sri Lanka tsunami disaster, when every nation has rescued its citizens with its own air carrier capacity. As a result, free air transport capacity was not available for other nations.

\subsubsection{Transport demand disappearance}

Before a big investment, there is always the question that in the long time its implementation is going to be be worthy. In this case, after the creation of a larger fleet, the need for aviation military transport is reduced, or more traffic is gained in the other transport sectors, even though today's trends do not seem to be overstated.

From this analysis it can be seen that in the current situation the strengths remained below so in any case it is worth thinking about developing this ability of the Defense Forces. In the following I will examine in more details the possibilities for development of the Hungarian fixed-wing aircraft fleet, taking into account the domestic specialties.

\section{Calculation of the military air transport fleet capacity-building proposal}

The calculation is based on the capacity of the Antonov 26 airplane, and with its help a fictitious company will be moved and sent on mission. In the calculation, a relatively large 200 person fictitious company will be relocated, which will carry the necessary equipment for each person (Budapest, Liszt Ferenc Nemzetközi Repülötér). We only took the weight limits. If an average soldier weight is $80 \mathrm{~kg}$ and his equipment is $25 \mathrm{~kg}$, we can count $105 \mathrm{~kg} /$ person. For 200 persons is the total:

$200 *(80+25)=21000 \mathrm{~kg}$. 
For 200 people during the transfer the computation includes 10 off-road vehicles. Currently, with the largest number of Mercedes-Benz G270 types perform tasks, which weights about $2640 \mathrm{~kg}$ each, so the 10 pieces are $26400 \mathrm{~kg}$.

The maximum payload of the Antonov 26 aircraft is $5500 \mathrm{~kg}$, so:

$$
(21000+26400) / 5500=8.6
$$

so it means 9 transport aircraft.

9 pieces of Antonov 26 medium cargo aircraft is required to carry 200 people and 10 off-road vehicles. Based on all these data, I examined the same company, with the help of Boeing C130, how many aircraft could make it. Fig. 1 shows Boeing C130 aircraft (Bera, 2008).

The reason I choosed the Boeing C130 type aircraft, is that although in its category it is very similar to Antonov 26, it can carry far more and bigger burdens and nowadays for example, it is affordable to purchase a second-hand at a reasonabel price.

Taking into account the previously calculated mass and the useful space of Boeing C130, which is $16194 \mathrm{~kg}$ :

$$
47400 / 16194=2.9
$$

so it means the need of 3 aircraft.

From the calculation and the basic data, it can be seen that it can transport 3 times more, than Antonov 26, not to mention the much larger cargo space.

It is not negligible, that the designers of the JAS39 Gripen fighter jet aircraft, used Boeing C130 type aircraft to transport the technical kit of the fighters, which was also regulated by the Swedish Air Force. Fig. 2 shows the Boeing C130 transport aircraft and the technical kit for the JAS39 Gripen fighter aircraft (Orosz, 2011).

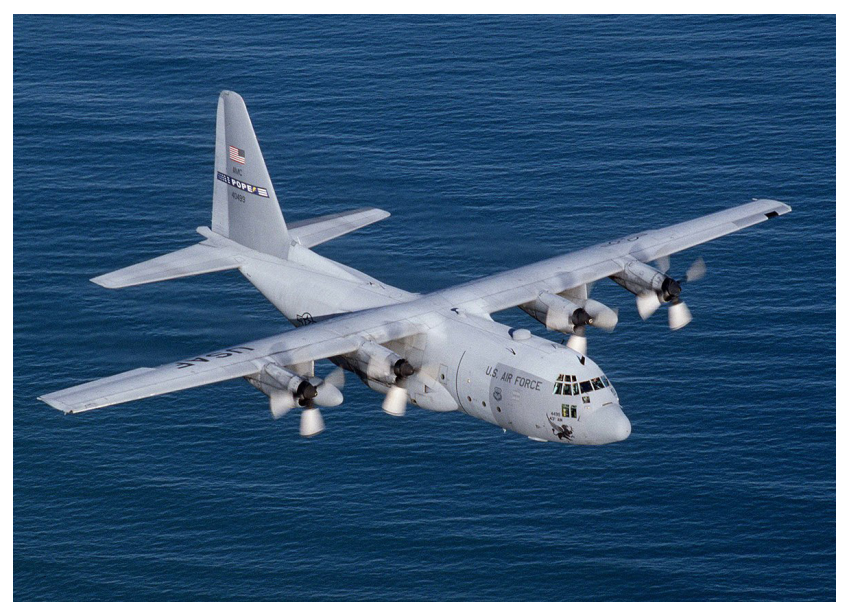

Fig. 1 The medium transport aircraft, Boeing C130 (Bera, 2008)

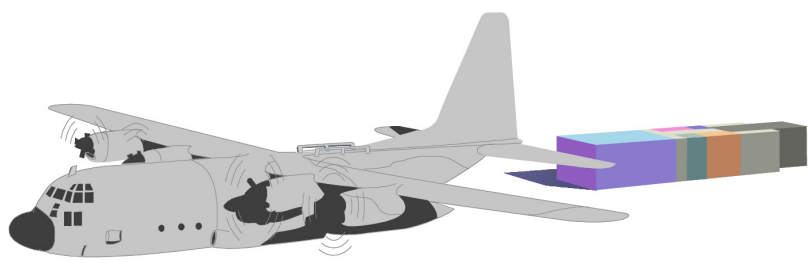

Fig. 2 The Boeing C130 transport aircraft, and the technical set of JAS39 Gripen (Orosz, 2011)

We can see on the figure the technical kit is in a $45 \mathrm{~m}^{3}$ volume standard delivery container, which includes the necessary tools, spare parts, ground handling tools, equipment, and instruments.

In my opinion, instead of the 5 pieces outdated, and environmentally-unfriendly Antonov 26 medium transport aircraft, we should purchase the same number, so 5 pieces of Boeing C130 aircraft, such as the Romanian Air Force did. Then the Hungarian Defense Forces would have a much larger capacity (three times bigger) of the transport fleet. Taking into account, that the Airbuses, which is scheduled to take place from February 2018, can also carry the personnel (like Czech Air Force) independently. Another important aspect, that JAS39 Gripen fighter pilots are required to do refueling trainings. To do these exercises, maintain trainings and keep the achieved skills the Hungarian Defense Forces has to pay for allied NATO members, because we do not have the capability. In terms of cost efficiency, procurement of Boeing C130 aircraft would solve this problem too.

Due to the geographic position of Hungary, it is also worthy considering a similar solution like the Belgian Air Force did. They operate Boeing C130 transport fleet of about 11 aircraft, thus generating high revenue for the army. These airplanes are not only carriing out domestic transport, but are regularly rented out by other countries with no transport capacity.

An additional carrier type aircraft can be considered, the Airbus A400M Atlas, with four propellers, top mid-wing military airliner, which is particularly popular in Europe nowadays. The Airbus S.A.S. developed the type, for French, English, German, Spanish, Italian, Belgian, Turkish and Luxembourg orders, mainly for the replacement of Boeing C160 Transall and Boeing C130 Hercules. First it was used by the French Air Force in 2013. Its production is in Seville at Airbus Defense and Space Factory. Fig. 3 shows the Airbus A400M Atlas aircraft.

Useful payload is up to $37000 \mathrm{~kg}$, which can be 116 fully equipped soldiers, or 66 patient lying on a stretcher and 


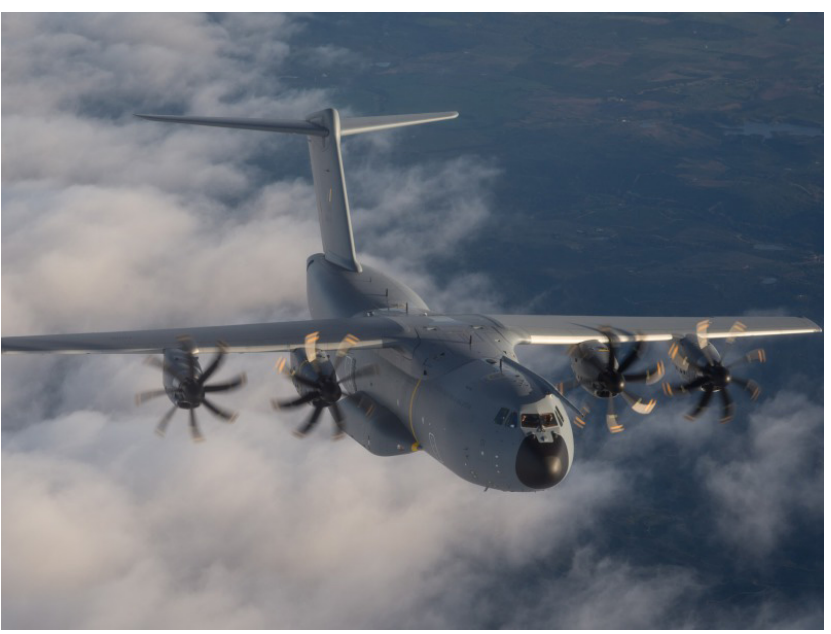

Fig. 3 Airbus A400M Atlas transport aircraft (Airbus S. A. S.)

25 caregivers. This type of machine is also a very good choice can be, as it makes the 20-35 tonnes of freight more cost-effective, which in many cases appears in real life of the Hungarian Army as presented in the above calculation. However, it is important to point out that the purchase price is approaching the Boeing C17 Globemaster's, so we can take into consideration to buy a type, with a higher capacity and faster speed. Hereinafter I will examine how we can purchase the aircraft fleet acording to the budget.

\section{Use of GDP to further develop the transport fleet}

Each NATO member is obliged to spend $2 \%$ of its GDP on an annual basis for the development or maintenance of the military. According to 2017 data, Hungary's GDP was 36987590 million HUF. $2 \%$ of this:

36987590 million HUF $* 0.02=739751$ million HUF.

According to Dr. István Simicskó, Minister of Defense, NATO member countries are not only expected to spend $2 \%$ GDP on defense, but also the proportion of the expenditures to be optimized: $40 \%$ to operate and $30-30 \%$ for wages and for development. According to the minister's budget plans, this year, the Hungarian Defense Forces is going to spend approximately 428 billion, $1.2 \%$ of GDP on defence, approaching the expected optimum ratio by NATO.

If I take into account that $30 \%$ of the previously calculated, approximately 740000 million HUF will be paid for the development, then:

740000 million HUF $* 0.3=222000$ million HUF.
On an annual basis, 220000 million HUF can be spent on the development of the aircraft fleet. The same case like the previously purchased Airbus A319s, it is of course much favorable to buy second-hand aircraft for the Army. Surfing on the internet, we can find more information about how much, a used Boeing C130 aircraft can cost, of course, depending on the flight time and condition. Looking at all of these, it can be stated that for 400 million dollar it is already possible to purchase a good-quality cargo plane, which amounts to 104000 million HUF at $260 \mathrm{HUF}$ exchange rate.

It can be seen, that a fraction of the budget designated by NATO, and a quarter of the amount we have previously allocated (HUF 428 billion) is also available for purchasing a transport aircraft. If the fleet is needed to be upgraded at a higher rate, buying 2 units per year starting from the current level (1 working Antonov 26, 2 pieces of Airbus A319s and 1 Dassault Falcon 7X), 3 years could be enough to upgrade the Hungarian Defense Forces fleet to the required level.

\section{Conclusion}

The SWOT analysis highlighted the features and characteristics of the current fleet as well as the untapped potentials that could be accomplished within a larger investment. Using some short calculations and taking into account previous analyzes and professional experiences, we calculated how many and what type of aircraft would be adequate. As a result, we have come to the conclusion that it would be worth thinking about at least 5 pieces of Boeing C130 or currently popular Airbus A400M Atlas aircraft. We came to that conclusion, that it would be indispensable to further develop domestic military airplanes and expand the vehicle fleet. The newly purchased Airbus A319 is hoped to be the forerunner of these developments, good direction, but there is still a need to purchase additional aircraft for full service. The development of all of our capabilities is essential, because we live in the middle of Europe, it is important to keep up with the surrounding countries. As a transit country, there are many opportunities for economic development. 


\section{References}

Airbus S. A. S. "A400M", [online] Available at: http://www.airbus.com/ defence/a400m.html [Accessed: 06 April 2018]

Budapest, Liszt Ferenc Nemzetközi Repülőtér "Antonov An-26", [online] Available at: https://lisztferihegy0.webnode.hu/repulogepek/ kisokos/antonov-an-26/ [Accessed: 06 April 2018]

Derzsényi, A. (2014) "Katonai légiszállítási képesség (logisztika előtt álló feladatok és azok lehetséges megoldásai)" (Military Air Transport Capacity (Logistics Challenges and Possible Solutions)), Hadmérnök, 9(1), pp. 40-56. (in Hungarian)

Bera, B. (2008) "C-130 Hercules", HTKA, Haditechnikai Kerekasztal [online] Available at: https://htka.hu/2008/01/03/c-130-hercules/ [Accessed: 20 April 2018] (in Hungarian)
HM Zrínyi Nonprofit Kft. "Magyar Honvédség online" (Hungarian Defence Forces online), [online] Available at: www.honvedelem.hu [Accessed: 23 March 2018] (in Hungarian)

MindTools "SWOT Analysis: How to Develop a Strategy for Success", [online] Available at: https://www.mindtools.com/pages/article/ newTMC_05.htm [Accessed: 12 March 2018]

Orosz, Z. (2011) "A Magyar honvédség szállítórepülés helikopter-alegységek alkalmazási lehetőségei a NATO szövetségesi rendszerében" (Possibilities of the Hungarian Defense Forces Aircraft Helicopter Subunits in the NATO Allied System), PhD Thesis, National University of Public Service. (in Hungarian) 